\title{
Association among the expression of $\beta$-catenin, cyclin D1 and estrogen receptor- $\beta$ in human breast cancer
}

\author{
LIYING GUO, DILIMINA YILAMU, LITING SUN, SHA LIU and FANGJING MA \\ Department of Breast Cancer, Digestive and Vascular Center, First Affiliated Hospital of \\ Xinjiang Medical University, Ürümqi, Xinjiang 830054, P.R. China
}

Received August 26, 2014; Accepted May 15, 2015

DOI: $10.3892 /$ etm.2015.2657

\begin{abstract}
D1 and estrogen receptor (ER)- $\beta$ are closely associated with the pathogenesis of breast cancer. In the present study, tissue samples were collected from 226 patients with breast cancer. Subsequently, immunohistochemical analysis was performed to detect the expression of $\beta$-catenin, cyclin D1 and ER- $\beta$, and the Kaplan-Meier method was used for survival analysis. The abnormal expression rate of $\beta$-catenin was $75.2 \%$, while the cyclin D1 positive expression rate was $77.0 \%$ and the ER- $\beta$ positive expression rate was $43.4 \%$. In the tissue samples exhibiting abnormal expression of $\beta$-catenin, the positive expression rate of cyclin D1 (85.9\%) was significantly higher compared with the samples that expressed $\beta$-catenin normally $(50.0 \%)$. Furthermore, the positive expression rate of ER- $\beta$ (35.7\%) in the $\beta$-catenin normal expression tissues was significantly lower compared with that in the $\beta$-catenin abnormal expression tissues (45.9\%). In the tissues with positive cyclin D1 expression, the positive expression rate of ER- $\beta$ (48.4\%) was significantly higher compared with the cyclin D1 negative expression samples (26.9\%). In addition, patients with normal expression of $\beta$-catenin and positive expression of cyclin D1 exhibited longer tumor-free survival times. Therefore, an association exists among the abnormal expression of $\beta$-catenin and the positive expression of cyclin D1 and ER- $\beta$, which may contribute to the development of breast cancer.
\end{abstract}

Correspondence to: Dr Liying Guo, Department of Breast Cancer, Digestive and Vascular Center, First Affiliated Hospital of Xinjiang Medical University, 137 Liyushan Road, Ürümqi, Xinjiang 830054, P.R. China

E-mail: gejsy318@126.com

Abbreviations: DFS, disease free survival; ER, estrogen receptor; OS, overall survival; PBS, phosphate-buffered solution; TCF/LEF, T-cell factor/lymphoid enhancer factor; HRP, horseradish peroxidase; SP, streptavidin peroxidase; DAB, 3,3'-diaminobenzidene

Key words: human breast cancer, Wnt signaling pathway, $\beta$-catenin, cyclin D1, estrogen receptor- $\beta$

\section{Introduction}

In the field of breast cancer research, focus has gradually changed from the clinical parameters and pathological index levels to the biology and gene expression levels of molecules, including certain cell signal transduction pathways that regulate cell cycle development $(1,2)$. The Wnt signaling transduction pathway is closely associated with the pathogenesis of breast cancer. $\beta$-catenin is a multifunctional protein and a key carcinogenic regulator of the Wnt signaling transduction pathway. $\beta$-catenin may accumulate aberrantly in the cytoplasm due to its degradation barrier, and may then be transferred into the nucleus when it reaches a certain concentration. Through the interaction with T-cell factor/lymphoid enhancer factor (TCF/LEF) and coactivators, $\beta$-catenin is able to activate a number of downstream target genes, such as cyclin D1, which results in uncontrolled cell proliferation and differentiation, and ultimately tumorigenesis (3). Traditionally, the breast cancer estrogen receptor (ER) refers to the ER- $\alpha$. A previous study has indicated that the positive expression rate of cyclin D1 was significantly increased in breast cancer tissue with positive expression of ER- $\alpha$ compared with that with negative expression of ER- $\alpha$ (4). ER-mediated signaling may activate $\beta$-catenin, and the Wnt signaling transduction pathway is subsequently activated and the expression of cyclin D1 increased in breast cancer tissue (5). These results suggest that the ER-mediated signaling pathway may be associated with the Wnt signaling pathway. However, in 1996, Kuiper et al identified an additional breast cancer cell estrogen receptor subtype, namely ER- $\beta$ (6). Long-term exposure to estrogen may lead to breast tumorigenesis. Previous studies have indicated that ER- $\beta$ is differentially expressed in breast cancer tissues $(7,8)$, which may be associated with tumorigenesis and the development of breast cancer.

In the present study, the expression levels of $\beta$-catenin, cyclin D1 and ER- $\beta$ were detected using immunohistochemistry. Subsequently, the associations among the expression levels of $\beta$-catenin, cyclin D1 and ER- $\beta$ were assessed. In addition, the effects of Wnt signaling transduction pathway and the positive expression of ER- $\beta$ on the survival times of breast cancer patients were further analyzed.

\section{Materials and methods}

Patient data. Paraffin-embedded breast cancer tissues were collected from 226 patients with pathologically confirmed 
breast cancer. All the patients were diagnosed and treated in the First Affiliated Hospital of Xinjiang Medical University (Ürümqi, China) between January 2000 and December 2010. The patients exhibited infiltrating ductal carcinoma, with the clinical stages varying between stage 0 and stage II. The clinical characteristics of the patients are presented in Table I, and the follow-up period for the patients ranged between 2 and 12 years, during which 15 patients were censored. Patients were censored if they succumbed to other causes, or were lost to follow-up at the time of last contact or prior to the study cut-off.

Prior written and informed consent was obtained from each patient and the study was approved by the Ethics Review Board of Xinjiang Medical University.

Reagents. An anti-human $\beta$-catenin monoclonal antibody (1:50; ZM0422) and an anti-human cyclin D1 monoclonal antibody (1:50; ZA0101) were purchased from Beijing Zhongshan Golden Bridge Biotechnology Co., Ltd. (Beijing, China). An anti-human ER- $\beta$ polyclonal antibody (1:60; BY-02101) was obtained from Shanghai Yueyan Biological Technology, Co., Ltd. (Shanghai, China), while horseradish peroxidase (HRP)-conjugated anti-rabbit and anti-mouse IgG secondary antibodies were purchased from Santa Cruz Biotechnology, Inc. (sc-47047; Santa Cruz, CA, USA). A streptavidin peroxidase (SP) immunohistochemical hypersensitivity kit and 3,3'-diaminobenzidine (DAB) reagents were obtained from Fuzhou Maixin Biotechnology Co., Ltd. (Fuzhou, China).

Immunohistochemical staining. Immunohistochemical staining was conducted according to the instructions provided with the SP immunohistochemical hypersensitivity kit, with minor modifications. Briefly, tissues were fixed in formaldehyde and embedded in paraffin. After dewaxing and rehydration, sections were incubated with $0.3 \%$ hydrogen peroxide to inactivate endogenous peroxidase activity. Antigen retrieval was achieved by incubating with sodium citrate ( $\mathrm{pH}$ 6.0). After blocking, the sections were incubated with the anti- $\beta$-catenin, anti-cyclin D1 and anti-ER- $\beta$ primary antibodies at $37^{\circ} \mathrm{C}$ in the dark for $1 \mathrm{~h}$. Following washing with phosphate-buffered saline (PBS), the HRP-conjugated IgG secondary antibodies were added and incubated in the dark for $30 \mathrm{~min}$. Subsequently, the sections were developed with DAB chromogenic reagent and counterstained with hematoxylin. Breast cancer tissues with known positive expression of $\beta$-catenin, cyclin D1 and ER- $\beta$ were used as positive controls. For a negative control, the primary antibody was replaced with PBS.

Determination criteria of expression. Positive expression of $\beta$-catenin was observed as brownish-yellow granular staining. Under normal conditions, $\beta$-catenin expression is located in the cell membrane of cancer cells. Cells with membranes exhibiting positive expression of $\beta$-catenin of $>70 \%$ were defined as normal expression cells. Under abnormal conditions, $\beta$-catenin expression is distributed in the cell cytoplasm and nucleus of cancer cells. Cells that exhibited positive expression of $\beta$-catenin in the cytoplasm or nucleus of $>10 \%$ were defined as abnormal expression cells.
Table I. Clinical data of the patients $(n=226)$.

Clinical feature

Cases, n $(\%)$

$\begin{array}{lr}\text { Age (years) } & \\ \leq 50 & 163(72.1) \\ >50 & 63(27.9) \\ \text { Menstruation } & \\ \text { Menopause } & 114(50.4) \\ \text { Non-menopause } & 112(49.6) \\ \text { Tumor diameter (cm) } & \\ \leq 2 & 141(62.4) \\ >2-3 & 85(37.6) \\ \text { Histological grade } & \\ \text { Grade I } & 56(24.8) \\ \text { Grade II } & 120(53.1) \\ \text { Grade III } & 50(22.1) \\ \text { Lymph node metastasis } & \\ \text { Negative } & 169(74.8) \\ \text { Positive } & 57(25.2) \\ \text { Tumor stage } & \\ \text { Stage 0-I } & 117(51.8) \\ \text { Stage II } & 109(48.2)\end{array}$

Positive expression of cyclin D1 was located in the nucleus, and the positive cells exhibited a brownish-yellow granular pigment. A total of 500 cells were counted under a DM LB2 microscope (Leica Microsystems GmbH, Wetzlar, Germany) at a high magnification. The positive staining rate of the cells was calculated, and the cells with a positive rate of $>10 \%$ were defined as overexpression cells.

ER- $\beta$ positive expression was shown as brown granules in the nucleus. In total, five fields were selected at random under high magnification. Cells exhibiting positive staining were counted, and the percentage of ER- $\beta$ positive staining was calculated as the number of positively stained cells to the total cell number. An ER- $\beta$ positive staining rate of $\geq 10 \%$ was defined as ER- $\beta$ positive expression.

Statistical analysis. Statistical analysis was performed using SPSS software, version 13.0 (SPSS, Inc., Chicago, IL, USA). Differences between groups were analyzed using the $\chi^{2}$ test, while the Kaplan-Meier method was used for survival analysis. $\mathrm{P}<0.05$ was considered to indicate a statistically significant difference.

\section{Results}

Expression of $\beta$-catenin, cyclin Dl and ER- $\beta$ in human breast cancer tissues. In order to determine the expression levels of $\beta$-catenin, cyclin D1 and ER- $\beta$, immunohistochemical staining assays were performed in 226 cases of human breast cancer tissues. Representative immunohistochemical staining results are shown in Fig. 1. Positive staining in the cells was shown as a brownish-yellow granular pigment. Normal expression of $\beta$-catenin in the cell membrane is shown in Fig. 1A. These 
Table II. Association between $\beta$-catenin and cyclin D1 expression.

\begin{tabular}{|c|c|c|c|c|c|}
\hline$\beta$-catenin expression & Cases (n) & Cyclin D1 negative, n (\%) & Cyclin D1 positive, $\mathrm{n}(\%)$ & $\chi^{2}$ & P-value \\
\hline Normal & 56 & $28(50.0)$ & $28(50.0)$ & & \\
\hline Abnormal & 170 & $24(14.1)$ & $146(85.9)$ & 30.616 & $<0.001$ \\
\hline Total cases & 226 & $52(23.0)$ & $174(77.0)$ & & \\
\hline
\end{tabular}

Table III. Association between $\beta$-catenin and ER- $\beta$ expression.

\begin{tabular}{|c|c|c|c|c|c|}
\hline$\beta$-catenin expression & Cases (n) & ER- $\beta$ negative, n (\%) & ER- $\beta$ positive, n (\%) & $\chi^{2}$ & P-value \\
\hline Normal & 56 & $36(64.3)$ & $20(35.7)$ & & \\
\hline Abnormal & 170 & $92(54.1)$ & $78(45.9)$ & 1.773 & 0.183 \\
\hline Total cases & 226 & $128(56.6)$ & $98(43.4)$ & & \\
\hline
\end{tabular}

ER, estrogen receptor.

Table IV. Association between cyclin D1 and ER- $\beta$ expression.

\begin{tabular}{lcccr}
\hline Cyclin D1 expression & Cases $(\mathrm{n})$ & ER- $\beta$ negative, $\mathrm{n}(\%)$ & ER- $\beta$ positive, $\mathrm{n}(\%)$ & $\chi^{2}$ \\
\hline Negative & 52 & $38(73.1)$ & $14(26.9)$ & \\
Positive & 174 & $90(51.7)$ & $84(48.4)$ & 7.432 \\
Total cases & 226 & $128(56.6)$ & $98(43.4)$ & 0.006 \\
\hline
\end{tabular}

ER, estrogen receptor.

cells were counted and the normal $\beta$-catenin expression rate was calculated. Cells exhibiting positive expression of $\beta$-catenin in the membrane of $>70 \%$ were defined as cells with normal expression. Ectopic expression of $\beta$-catenin in the cytoplasm or the nucleus was considered abnormal expression (Fig. 1B). After counting, the abnormal expression rate was calculated, in which cells with cytoplasm- or nucleus-positive expression of $\beta$-catenin of $>10 \%$ were defined as abnormal expression cells. A negative control for cyclin D1 expression and a representative sample with positive cyclin D1 expression are shown in Fig. 1C and D, respectively. In addition, a negative control for ER- $\beta$ expression and a representative sample with positive ER- $\beta$ expression are shown in Fig. 1E and F, respectively. Positively stained cells were counted and the positive expression rate was calculated. Cells with a positive cyclin D1 expression rate of $>10 \%$ were defined as overexpression cells, while cells with a positive ER- $\beta$ expression rate of $\geq 10 \%$ were defined as overexpression cells.

Breast cancer tissues with abnormal $\beta$-catenin expression exhibit a higher cyclin D1 positive expression rate. To assess the association between $\beta$-catenin and cyclin D1 expression, the cases with abnormal $\beta$-catenin expression and positive cyclin D1 expression were calculated. Subsequently, the cyclin D1 positive expression rate in $\beta$-catenin normal and abnormal expression tissues was analyzed (Table I). In total, 56 cases exhibited normal $\beta$-catenin expression and 170 cases exhibited abnormal $\beta$-catenin expression, with an abnormal $\beta$-catenin expression rate of $75.2 \%$. Furthermore, a total of 52 cases were cyclin D1-negative and 174 cases exhibited positive cyclin D1 expression, with a positive cyclin D1 expression rate of $77.0 \%$. The cyclin D1 positive expression rate in the normal $\beta$-catenin expression tissues was $50.0 \%$ (28/56), while in the abnormal $\beta$-catenin expression tissues, the cyclin D1 positive expression rate was $85.9 \%$ (146/170). The cyclin D1 positive expression rate in the abnormal $\beta$-catenin expression tissues was higher compared with the normal $\beta$-catenin expression tissues, and the difference was statistically significant $(\mathrm{P}<0.05$; Table II). Thus, breast cancer tissues with abnormal $\beta$-catenin expression exhibited an elevated cyclin D1 positive expression rate.

Breast cancer tissues with abnormal $\beta$-catenin expression exhibit a higher ER- $\beta$ positive expression rate. To analyze the association between ER- $\beta$ expression and $\beta$-catenin expression, the number of cases with ER- $\beta$ positive expression was calculated. Subsequently, the ER- $\beta$ positive expression rate in the $\beta$-catenin normal and abnormal expression tissues was compared (Table III). ER- $\beta$ expression was positive in 98 breast cancer tissue samples and negative in 128 cases, with a positive expression rate of $43.4 \%$. In the normal $\beta$-catenin expression tissues, the ER- $\beta$ positive expression rate was $35.7 \%$ $(20 / 56)$, while in the abnormal $\beta$-catenin expression tissues, the rate was $45.9 \%$ (78/170). The difference between these two 

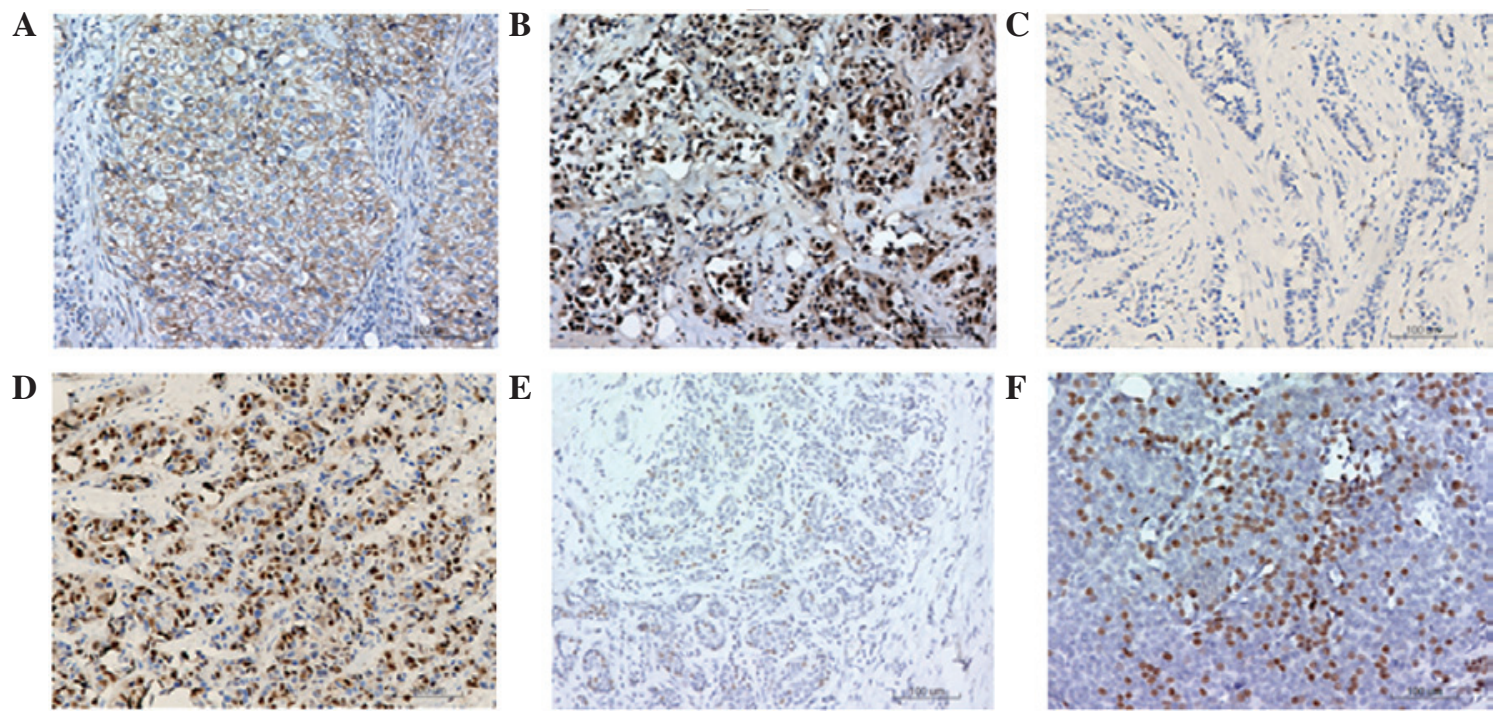

Figure 1. Immunohistochemical staining of $\beta$-catenin, cyclin D1 and estrogen receptor (ER)- $\beta$ in human breast cancer tissues. Representative results are shown, where cells exhibiting a brownish-yellow granular pigment are positively stained. (A) Normal expression of $\beta$-catenin in the cell membranes of breast cancer tissues (magnification, $\mathrm{x} 400$ ). (B) Abnormal expression of $\beta$-catenin in the cell cytoplasm and nuclei of breast cancer tissues (magnification, $\mathrm{x} 400$ ). (C) Negative control for cyclin D1 (magnification, x200), where the primary antibody (anti-cyclin D1) was replaced with phosphate-buffered saline (PBS). (D) Cyclin D1 positive expression in breast cancer cell nuclei (magnification, x200). (E) Negative control for ER- $\beta$ (magnification, x200), where the primary antibody (anti-ER- $\beta$ ) was replaced with PBS. (F) ER- $\beta$ positive expression in breast cancer tissue (magnification, $x 200$ ).

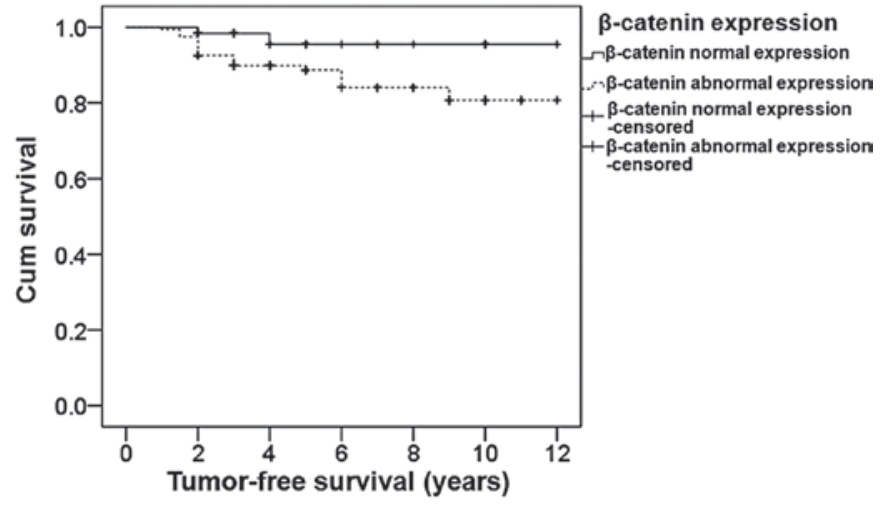

Figure 2. Survival analysis of breast cancer patients with normal and abnormal $\beta$-catenin expression. A Kaplan-Meier survival curve was constructed. During the follow-up period, 15 patients were censored, which included patients who succumbed to other causes or were lost to follow-up at the time of last contact or prior to the study cut-off.

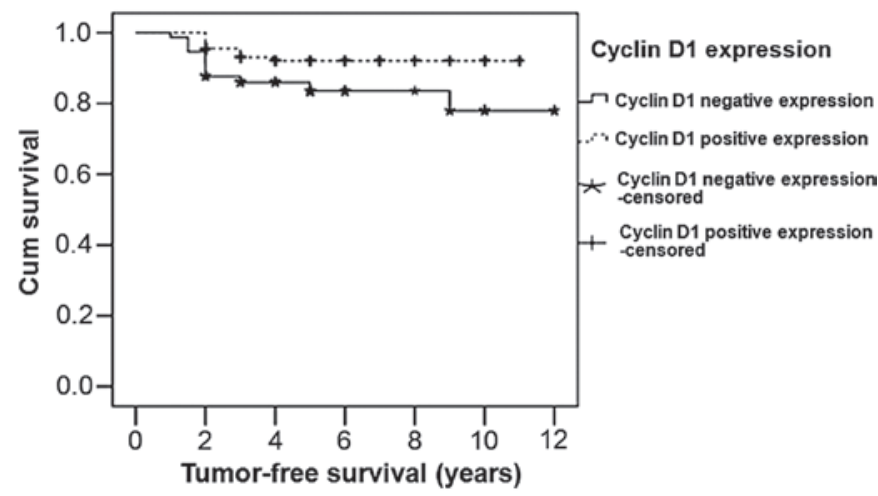

Figure 3. Survival analysis of breast cancer patients with negative and positive cyclin D1 expression. A Kaplan-Meier survival curve was constructed. During the follow-up period, 15 patients were censored, which included patients who succumbed to other causes or were lost to follow-up at the time of last contact or prior to the study cut-off. groups was statistically significant $(\mathrm{P}<0.05)$. Therefore, higher ER- $\beta$ positive expression levels in breast cancer tissues were associated with abnormal $\beta$-catenin expression.

Breast cancer tissues with cyclin D1 positive expression exhibit a higher ER- $\beta$ positive expression rate. The association between cyclin D1 expression and ER- $\beta$ expression was determined by calculating the positive expression rate of ER- $\beta$ in cyclin D1 positive expression tissues. As shown in Table IV, the ER- $\beta$ positive expression rate in the cyclin D1 negative expression group was $26.9 \%(14 / 52)$, while in the cyclin D1 positive expression group, the rate was $48.4 \%(84 / 174)$. The ER- $\beta$ positive expression rate in the cyclin D1 positive expression tissues was significantly higher compared with the cyclin D1 negative expression tissues $(\mathrm{P}<0.05)$, indicating that breast cancer tissues with cyclin D1 positive expression possess a higher ER- $\beta$ positive expression rate compared with cyclin D1 negative expression.

Patients with normal $\beta$-catenin expression exhibit an extended survival time. To determine the effect of $\beta$-catenin expression on survival, the tumor-free survival times were analyzed using the Kaplan-Meier method. The resulting survival curves are presented in Fig. 2. The median survival time of patients with normal $\beta$-catenin expression was 11.6 years, while that of patients with abnormal $\beta$-catenin expression was 10.5 years. The difference between the patients with normal $\beta$-catenin expression and those with abnormal $\beta$-catenin expression was statistically significant $(\mathrm{P}=0.049)$. Therefore, the median survival time was longer in patients with normal $\beta$-catenin expression.

Patients with cyclin DI positive expression have longer survival times. For survival analysis in the patients with a different cyclin D1 expression status, the tumor-free survival 
time was analyzed using the Kaplan-Meier method. The survival curves are shown in Fig. 3. The median survival time of the cyclin D1 positive expression patients was 10.230 years, which was higher compared with that of the cyclin D1 negative expression patients (10.177 years). A statistically significant difference was identified between the patients with positive cyclin D1 expression and those with negative cyclin D1 expression $(\mathrm{P}=0.026)$. Therefore, patients with cyclin $\mathrm{D} 1$ positive expression exhibited a longer survival time compared with those with cyclin D1 negative expression.

\section{Discussion}

The Wnt signaling pathway is activated in the vast majority of breast cancer tissues, and has been shown to be involved in the tumorigenesis of breast tissue (9). In the classical Wnt pathway, $\beta$-catenin serves a key function. In cells that have been activated by Wnt protein ligands, cytoplasmic $\beta$-catenin is prevented from degradation and stably accumulates in the cytoplasm. The accumulated $\beta$-catenin is subsequently transferred into the nucleus where it binds with the TCF/LEF, enhancing the transcription of genes involved in cell proliferation, and thus inducing carcinogenesis. Cyclin D1 is a crucial target gene in the Wnt signaling pathway (10). Previous studies have reported that abnormal expression of $\beta$-catenin and cyclin D1 is associated with breast cancer occurrence and development $(11,12)$. In addition, clinical studies have indicated that the $\beta$-catenin and cyclin D1 expression rates in breast cancer tissues were $51-89 \%$ and $45-83 \%$, respectively $(13,14)$. In accordance, the results of the present study revealed the abnormal expression rate of $\beta$-catenin as $75.2 \%$ and the positive expression rate of cyclin D1 as $77.0 \%$ in the 226 breast cancer samples.

Currently, the association between $\beta$-catenin and cyclin D1 expression in breast cancer tissue remains controversial. For example, studies by Ozaki et al (15) and Lin et al (12) demonstrated that the abnormal expression of $\beta$-catenin was associated with the overexpression of cyclin D1. However, Lim and Lee (11) indicated that the abnormal expression of $\beta$-catenin was not associated with cyclin D1 overexpression. Yang et al (16) analyzed $\beta$-catenin and cyclin D1 expression in 60 breast cancer tissues using an immunohistochemical method. The authors identified 42 cases with abnormal $\beta$-catenin expression, in which $57.1 \%$ exhibited cyclin D1 overexpression, indicating a significant positive correlation. Thus, it was concluded that abnormal expression of $\beta$-catenin may lead to the occurrence and development of breast cancer by inducing or activating cyclin D1 overexpression. In the 226 breast cancer samples analyzed in the present study, the cyclin D1 positive expression rate in the $\beta$-catenin abnormal expression tissues was significantly higher compared with the $\beta$-catenin normal expression tissues. This result indicated that Wnt signaling is over-activated in breast cancer tissues, resulting in abnormal expression of $\beta$-catenin, which may induce or activate cyclin D1 overexpression, leading to the occurrence and development of breast cancer.

Lazennec et al (17) observed that ER- $\beta$ expression levels in breast cancer tissues were significantly reduced compared with normal breast tissues, and the loss of ER- $\beta$ expression resulted in the occurrence of breast cancer. Numerous studies have demonstrated that overexpression of cyclin D1 is consistent with ER- $\alpha$ positive expression $(4,18,19)$. However, there are a limited number of studies investigating the association between the Wnt pathway and ER- $\beta$ expression. Zwijsen et al (20) reported that cyclin D1 overexpression in breast cancer tissues was associated with the expression of the estrogen response element. Cyclin D1 may perform a similar function to estrogens. Furthermore, the authors hypothesized that the effects of estrogen on breast tumors may be exerted via the cyclin D1 pathway, and that ER- $\alpha$ may promote breast cancer occurrence through the induction of cyclin D1. However, Luo et al (5) indicated that the ER pathway was connected with the Wnt signaling pathway through $\beta$-catenin. ER pathway activation may activate $\beta$-catenin, which may further activate the Wnt signaling pathway and result in the increased expression of cyclin D1. The present results indicated that the difference in the ER- $\beta$ positive expression rate between the normal and abnormal $\beta$-catenin expression tissues was statistically significant. Furthermore, the ER- $\beta$ positive expression rate in the cyclin D1 positive expression tissues was significantly higher compared with the cyclin D1 negative tissues, indicating that cyclin D1 overexpression may be closely associated with ER- $\beta$ positive expression.

A previous study indicated that $\beta$-catenin expression is increased in breast cancer tissues, and is associated with a poor prognosis (21). Lin et al (12) detected the $\beta$-catenin expression levels of 123 breast cancer samples using an immunohistochemical method, and found that cytoplasmic expression of $\beta$-catenin represented the activated state of $\beta$-catenin and that $\beta$-catenin was an independent prognostic factor for breast cancer survival. Nakopoulou et al (22) examined 141 breast cancer specimens, and reported that nuclear $\beta$-catenin expression correlated with reduced overall survival (OS) and disease free survival (DFS) times, while cytoplasmic $\beta$-catenin expression was associated with longer OS and DFS times. In the studies by Lin et al (12), Lim and Lee (11) and López-Knowles et al (23), the abnormal expression of $\beta$-catenin in breast cancer tissues was shown to be associated with a poor prognosis, while $\beta$-catenin may be used as an independent prognostic factor for breast cancer evaluation. However, Chung et al (24) indicated that abnormal expression of $\beta$-catenin was not associated with prognosis, and was only associated with a poor prognosis in cases that presented with abnormal expression of $\beta$-catenin and overexpression of $\mathrm{p} 53$ simultaneously. Thus, Chung et al hypothesized that $\beta$-catenin was unable to be used an independent prognostic factor for breast cancer. In the present study, the median tumor free survival time of the patients with normal $\beta$-catenin expression was higher compared with the patients with abnormal $\beta$-catenin expression, and the difference was statistically significant. Furthermore, patients with positive cyclin D1 expression exhibited a longer survival time compared with those with negative cyclin D1 expression. These results are consistent with those of previous studies (25-30), and indicate that patients with positive cyclin D1 expression may expect an improved prognosis.

In conclusion, the results of the present study indicate that the expression of $\beta$-catenin, cyclin D1 and ER- $\beta$ in breast cancer tissues are associated with each other, and may serve crucial functions in the development of breast cancer. 


\section{Acknowledgements}

This study was supported by grants from the National Natural Science Foundation of Xinjiang Uygur Autonomous Region (no. 2011211A069) and the National Clinical Key Subject General Surgery Construction Project.

\section{References}

1. Parkin DM, Bray F, Ferlay J and Pisani P: Global cancer statistics, 2002. CA Cancer J Clin, 55: 74-108, 2005.

2. Kohlberger PD, Breitenecker F, Kaider A, Lösch A, Gitsch G, Breitenecker $G$ and Kieback DG: Modified truecolor computer-assisted image analysis versussubjective scoring of estrogen receptor expression in breast cancer: A comparison. Anticancer Res 19: 2189-2193, 1999.

3. Kikuchi A: Regulation of beta-catenin signaling in the Wnt pathway. Biochem Biophys Res Commun 268: 243-248, 2000.

4. Mauro L, Pellegrino M, Giordano F, Ricchio E, Rizza P, De Amicis F, Catalano S, Bonofiglio D, Panno ML and Andò S: Estrogen receptor- $\alpha$ drives adiponectin effects on cyclin D1 expression in breast cancer cells. FASEB J 29: 2150-2160, 2015.

5. Luo J, Chen YL and Xu H: Expression of $\beta$-catenin, cyclin D1 and $\mathrm{ER} \alpha$ in breast cancer. Shi Yong Yu Fang Yi Xue 17: 1502-1504, 2010 (In Chinese).

6. Kuiper GG, Enmark E, Pelto-Huikko M, Nilsson S and Gustafsson JA: Cloning of a novel receptor expressed in rat prostate and ovary. Proc Natl Acad Sci USA 93: 5925-5930, 1996

7. Speirs V, Parkes AT, Kerin MJ, Walton DS, Carleton PJ, Fox JN and Atkin SL: Coexpression of estrogen receptor $\alpha$ and $\beta$ : Poor progonostic factors in human breast cancer. Cancer Res 59: 525-528, 1999.

8. Speirs V, Adams IP, Walton DS and Atkin SL: Identification of wild-type and exon 5 deletion variants of estrogen receptor beta in normal human mammary gland. J Clin Endocrinol Metab 85: 1601-1605, 2000.

9. Howe LR and Brown AM: Wnt signaling and breast cancer. Cancer Biol Ther 3: 36-41, 2004.

10. Bala S and Peltomäki P: CYCLIN D1 as a genetic modifier in hereditary non polyposis colorectal cancer. Cancer Res 61: 6042-6045, 2001.

11. Lim SC and Lee MS: Significance of E-cadherin/beta-catenin complex and cyclin D1 in breast cancer. Oncol Rep 9: 915-928, 2002.

12. Lin SY, Xia W, Wang JC, et al: Beta-catenin, a novel prognostic marker for breast cancer: Its roles in cyclin D1 expression and cancer progression. Proc Natl Acad Sci USA 97: 4262-4266, 2000

13. Brabletz T, Jung A, Reu S, et al: Variable beta-catenin expression in colorectal cancers indicates tumor progression driven by the tumor environment. Proc Natl Acad Sci USA 98: 10356-10361, 2001.
14. Paola C, Anna P, Marina R, Gnesi E, Baldini E and Bevilacqua G: Cyclin D1 expression in node positive $(\mathrm{N}+)$ and node-negative $(\mathrm{N}-)$ infiltrating human mammary carcinomas. Int J Cancer 84: 139-144, 1999.

15. Ozaki S, Ikeda S, Ishizaki Y, et al: Alterations and correlations of the components in the Wnt signaling pathway and its target genes in breast cancer. Oncol Rep 14: 1437-1443, 2005.

16. Yang JF, Chen SL, Liu ZH and Zhang Y: Correlation among expression of E-cadherin, beta-catenin, and cyclin D1 in breast cancers. Ai Zheng 23: 799-802, 2004 (In Chinese).

17. Lazennec G, Bresson D, Lucas A, Chauveau C and Vignon F: ER beta inhibits proliferation and invasion of breast cancer cells. Endocrinology 142: 4120-4130, 2001.

18. Castro Rivera E, Samudio I and Safe S: Estrogen regulation of cyclin D1 gene expression in ZP-75 breast cancer cells involves multiple enhancer elements. J Biol Chem 276: 30853-30861, 2001.

19. Ravikumar G and Ananthamurthy A: Cyclin D1 expression in ductal carcinoma of the breast and its correlation with other prognostic parameters. J Cancer Res Ther 10: 671-675, 2014.

20. Zwijsen R, Wientjens E, Klompmaker R, van der Sman J, Bernards R and Michalides RJ: CDK-independent activation of estrogen receptor by cyclin D1. Cell 88: 405-415, 1997.

21. Musgrove EA: Wnt signaling via the epidermal growth factor receptor: A role in breast cancer? Breast Cancer Res 6: 65-68, 2004.

22. Nakopoulou L, Mylona E, Papadaki I, Kavantzas N, Giannopoulou I, Markaki S and Keramopoulos A: Study of phospho-beta-catenin subcellular distribution in invasive breast carcinomas in relation to their phenotype and the clinical outcome. Mod Pathol 19: 556-563, 2006.

23. López-Knowles E, Zardawi SJ, McNeil CM, et al: Cytoplasmic localization of beta-catenin is a marker of poor outcome in breast cancer patients. Cancer Epidemiol Biomarkers Prev 19: 301-309, 2010.

24. Chung GG, Zerkowski MP, Ocal IT, et al: beta-Catenin and p53 analyses of a breast carcinoma tissue microarray. Cancer 100: 2084-2092, 2004.

25. Gillett C, Smith P, Gregory W, Richards M, Millis R, Peters G and Barnes D: Cyclin D1 and prognosis in human breast cancer. Int J Cancer 69: 92-99, 1996.

26. Steeg PS and Zhou Q: Cyclins and breast cancer. Breast Cancer Res Treat 52: 17-28, 1998.

27. Diana M and Barnes CEG: Cyclin D1 in breast cancer. Acta Oncology 24: 421, 1995.

28. Bates S, Parry D, Bonetta L, Vousden K, Dickson C and Peters G: Absence of cyclin D/CDK complexes in cells lacking functional retinoblastoma protein. Oncogene 9: 1633-1640, 1994.

29. Quintayo MA, Munro AF, Thomas J, et al: GSK3 $\beta$ and cyclin D1 expression predicts outcome in early breast cancer patients. Breast Cancer Res Treat 136: 161-168, 2012.

30. Peurala E, Koivunen P, Haapasaari KM, Bloigu R and Jukkola-Vuorinen A: The prognostic significance and value of cyclin D1, CDK4 and p16 in human breast cancer. Breast Cancer Res 15: R5, 2013. 